\title{
VELOCITY OF LONG BUBBLES TRANSPORTED BY A LIQUID IN HORIZONTAL CHANNEL
}

\author{
Ha Ngoc Hien ${ }^{1}$, Jean Fabre ${ }^{2}$ \\ ${ }^{1}$ Institute of Mechanics, VAST \\ ${ }^{2}$ Institut de Mécanique des Fluides de Toulouse, France
}

\begin{abstract}
The influence of flowing liquid on the motion of long bubbles in horizontal channel is studied theoretically. The method of Benjamin (1968) is extended to the case of moving liquid: the liquid is inviscid, the surface tension is ignored and the liquid motion at infinity is characterized its velocity profile. The exact solutions for the bubble velocity and the liquid film thickness are given under an integral form. An approximate analytical solution can be found when the mean liquid velocity is weak enough versus the drift velocity. Two cases are investigated: the Couette flow and the Poiseuille flow. At first order, the two cases lead to identical solutions. The influence of the velocity distribution appears only at the second order.
\end{abstract}

\section{INTRODUCTION}

The motion of bubbles in a channel or a tube is influenced by two mechanisms: gravity and transport by the mean liquid velocity. Nicklin et al. [1] have showed by experiments that the bubble velocity in vertical tube in a flowing liquid with the mean velocity $u_{0}$, can be expressed in the form:

$$
V=C_{0} u_{0}+V_{\infty}
$$

where $V_{\infty}$ is the bubble drift velocity in stagnant liquid due to the force of Archimedes and $C_{0}$ is a factor whose value depends on the liquid velocity profile imposed upstream the bubble.

The influence of the liquid motion on the bubble velocity was analyzed theoretically by Collins et al. [2] and Bendiksen [3] for axis-symmetrical bubble in vertical pipes. The flow is supposed to be inviscid and rotational, the upstream vorticity distribution being determined by a given velocity profile. Collins et al. [2] have obtained expressions for the bubble velocity, which agree well with the experimental results and the results of Bendiksen taken into account the influence of the surface tension. In the horizontal case, the theoretical analysis of Benjamin [4] showed that, the drift velocity is equal to $V_{\infty}=$ $0.542 \sqrt{g D}$ in a horizontal tube and $V_{\infty}=0.5 \sqrt{2 g a}$ in a channel ( $D$ is the tube diameter and $2 a$ is the height of the channel).

In this paper, the Benjamin approach is extended to the case of a bubble moving in a flowing liquid for two cases: the Couette flow and the Poiseuille flow of the liquid upstream the bubble. 


\section{FORMULATION OF THE PROBLEM}

The schematic representation of a plane bubble in a flowing liquid in horizontal channel is presented in Fig. 1. The presentation of the velocity field is made in a reference frame moving with the bubble. In this reference frame, the bubble remains motionless and the flow is stationary.

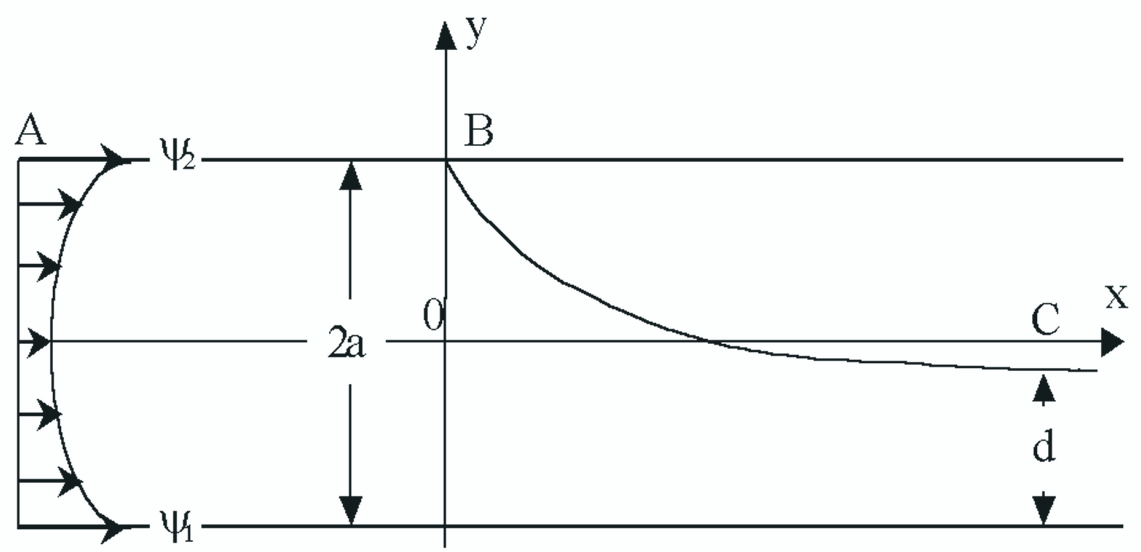

Fig. 1. Geometry representation in the moving frame

In this study, the fluid is supposed inviscid and the flow is rotational. The vorticity distribution being prescribed sufficiently far upstream from the bubble are determined by the imposed velocity profile. To suppose the inviscid fluid and the rotational flow returns in fact to neglect the side effects while holding account of the principal effects of viscosity. Such an approach was proposed before by Lamb [5] and Batchelor [6]. It is appropriate particularly for the flows in which exists an interface where viscous shearing can be neglected due to the fact that the vorticity diffusion closes to the interface remains negligible. It is the case for axis-symmetric bubbles in vertical pipes which was treated successfully by Collins et al. [2] and by Bendiksen [3].

In steady plane flow, the vorticity $\omega$ remains constant on streamlines. Hence, it can be written:

$$
\omega=f(\psi),
$$

where $\psi$ is the stream function which satisfies a Poisson's equation:

$$
\frac{\partial^{2} \psi}{\partial x^{2}}+\frac{\partial^{2} \psi}{\partial y^{2}}=-f(\psi)
$$

The function $f(\psi)$ is obtained from the conditions imposed upstream of the bubble at $x=-\infty$. Velocity $u_{a}$ in the fixed frame is indeed known there and depends only on $y$. In the frame attached to the bubble, velocity at $x=-\infty$ gets the form:

$$
u(-\infty, y)=V-u_{a}(y)
$$


By choosing the arbitrary constant, $\psi(-\infty, 0)=0$, the stream function and the vorticity at $x=-\infty$ express themselves by:

$$
\psi(-\infty, y)=\int_{0}^{y} u(-\infty, \eta) d \eta, \quad \omega(-\infty, y)=-\frac{d u(-\infty, y)}{d y}
$$

It is generally not possible to eliminate the coordinate $y$ between the Eqs in (5) to get a relation having the form of the Eq. (2). However, this relation can be put, by taking account of the equation (4), in the following parametric form:

$$
\psi(Y)=V Y-\int_{0}^{Y} u_{a} d \eta, \text { and } \omega(Y)=\frac{d u_{a}}{d Y}
$$

where $Y$ is a parameter which has the same dimension as $y$.

With regard to the boundary conditions associated with the Eq. (3), the stream function is given far upstream of the bubble, on the lower wall $\left(\psi=\psi_{1}\right)$, on the upper wall and on the interface $\left(\psi=\psi_{2}\right)$. However, the form of the interface is not known a priori. In the absence of surface tension, the pressure on the surface in the liquid is constant and the Bernoulli theorem, written between the stagnation point B and a point of interface, gives an additional equation which allows to determine the bubble form:

$$
\left[\frac{u^{2}+v^{2}}{2}+g(y-a)\right]_{\text {interface }}=0
$$

Finally, enough far from the stagnation point, the flow in film is fully developed and the interface is parallel to the channel bottom. The velocity field is uniform there, so that one can write $\partial \psi / \partial x=0$.

Such a solution will give velocity in any point of the field as well as the form of the interface. The originality of the Benjamin method consists in the fact that it is not necessary to calculate the velocity field to obtain the bubble velocity in the case of a horizontal channel. Indeed, a global momentum equation in direction $x$, associated with the Bernoulli equation on the streamlines $\psi_{1}$ and $\psi_{2}$, is enough, provided that the velocity distributions are known in the entrance and the exit. In the case of a bubble moving in stagnant liquid, the flow is irrotational and velocity distributions are uniform if the position of the entrance and the exit is chosen enough far from the stagnation point. Moreover, and it is the key point there, the shape of the bubble does not intervene in the momentum equation in direction $x$ since the liquid weight have no contribution in horizontal direction and that the pressure is zero on the interface. The analytical solution of Benjamin for velocity is moreover analytical because the flow is irrotational. We extended here the method to the case of the rotational flow in order to analyze the influence of the liquid motion when the flow is fully developed or under development. 
The global momentum equation written between section $\mathrm{A}$ and the section $\mathrm{C}$ (see Fig. 1) by choosing the pressure reference in the gas $\left(p_{B}=p_{C}=0\right)$ has the form:

$$
\int_{-a}^{a} u^{2}(-\infty, y) d y+\int_{-a}^{a} \frac{p(-\infty, y)}{\rho} d y=\int_{-a}^{d-a} u^{2}(\infty, y) d y+\int_{-a}^{d-a} \frac{p(+\infty, y)}{\rho} d y
$$

The study will limited for the flows for which the upper wall is motionless, this allows to impose $u_{A}=V$. Assuming the hydrostatic distribution of pressure in the sections A and $\mathrm{C}$, the integrals of pressure in the equation can be calculated, with the Bernoulli equations written on the streamline $\psi=\psi_{2}$ between $\mathrm{A}$ and B, the global momentum Eq. (7) becomes :

$$
\int_{-a}^{a} u^{2}(-\infty, y) d y+2 a\left(g a-\frac{V^{2}}{2}\right)=\int_{-a}^{d-a} u^{2}(+\infty, y) d y+\frac{d^{2} g}{2} .
$$

The Bernoulli equation written on the streamlines $\psi=\psi_{2}$ between $\mathrm{B}$ and $\mathrm{C}$ has the form:

$$
\frac{u_{C}^{2}}{2}+g(d-2 a)=0 .
$$

In the case treated by Benjamin, the liquid is motionless in section A, in the moving reference frame velocity is uniform and equal to $V$, and $u_{C}$ can be calculated from continuity equation $2 a V=d u_{C}$. The film thickness and the bubble velocity can be obtained: $d=a$ and $V=0.5 \sqrt{2 g a}$.

Let's return now to the general case of flowing liquid for which the upstream velocity distribution is known. Then the integral in the left-hand side member of the Eq. (8) is known. It remains to calculate that of the right-hand side member.

At infinity $x=+\infty$, the Poisson Eq. (2) for the stream function becomes:

$$
\frac{d^{2} \psi(+\infty, y)}{d y^{2}}=-f[\psi(+\infty, y)]
$$

where the function $f$ is known from the parametric form (6). This equation can be solved with the following conditions on the lower wall and interface:

$$
\psi(+\infty,-a)=\psi_{1}, \quad \psi(+\infty, d-a)=\psi_{2} .
$$

The Eq. (10) as well as the conditions (11) can be used to determine the velocity profile at infinity below the bubble. The solution allows to determine the integral in the second member of the Eq. (8) in function of the liquid film thickness $d$ and the bubble velocity $V$.

Finally, the three Eqs (8), (9) and (10) with the boundary conditions (11) form a system closed for the three unknowns $\psi(+\infty, y), V$ and $d$.

\section{SOLUTIONS}

We will use from now the dimensionless variables in which the length is scaled by the channel half-width $a$ and velocity by $\sqrt{2 g a}$. The Eqs (8), (9), (10) and (11) in dimensionless 
form become:

$$
\begin{gathered}
\frac{d^{2} \psi}{d y^{2}}=-f(\psi), \\
\frac{u_{C}^{2}}{2}+\frac{d}{2}-1=0, \\
\int_{-1}^{1} u^{2}(-\infty, y) d y+\left(1-V^{2}\right)=\int_{-1}^{d-1} u^{2}(+\infty, y) d y+\frac{d^{2}}{4},
\end{gathered}
$$

with the boundary conditions:

$$
\psi(-1)=\psi_{1}, \quad \psi(d-1)=\psi_{2} .
$$

\subsection{Couette flow upstream of the bubble}

We will consider now the case when the channel upper wall is fixed and the lower wall moves with the constant velocity $2 u_{0}$, where $u_{0}$ is the mean velocity. The vorticity is constant: $\omega=\omega_{0}=-u_{0}$. In the moving reference frame, the velocity profile upstream of the bubble is written:

$$
u(-\infty, y)=V+\omega_{0}(1-y) .
$$

The stream function at $x=-\infty$ can be obtained by (5):

$$
\psi(-\infty, y)=\left(V+\omega_{0}\right) y-\omega_{0} \frac{y^{2}}{2} .
$$

The stream function at $x=+\infty$ obtained by the solution of the Eq. (12) with the conditions (15) has the form:

$$
\psi(+\infty, y)=-\frac{\omega_{0}}{2} y^{2}+\frac{4\left(V+\omega_{0}\right)-d \omega_{0}(2-d)}{2 d} y+\frac{(2-d)\left(2 V+2 \omega_{0}-d \omega_{0}\right)}{2 d} .
$$

Now we can determine the velocity $u(+\infty, y)$ in the film in section $\mathrm{C}$ and replace it into the momentum Eq. (14) and Eq. (13). This allows to obtain the equations for the film thickness $d$ and the bubble velocity $V$ :

$$
\begin{gathered}
(2-d)^{2}(2+3 d)^{2} \omega_{0}^{4}-24(2-d)\left(2+d+3 d^{2}\right) \omega_{0}^{2}+144(1-d)^{2}=0, \\
V=\frac{12(1-d)-(2-d)(10+3 d) \omega_{0}^{2}}{24 \omega_{0}}
\end{gathered}
$$

The equation (16) can be put in the form of a polynomial of the second degree in $\omega_{0}^{2}$ with coefficients depending only on $d$. Four roots thus are obtained. The solution which tends in a monotonous way towards $V=0.5$ and $\omega_{0}=0$ (Benjamin [4]), when $d \rightarrow 1$ is written:

$$
\omega_{0}=\varepsilon \frac{2 \sqrt{3}}{2+3 d} \sqrt{\frac{2+d+3 d^{2}-2 d \sqrt{3(2+d)}}{2-d}},
$$


with $\varepsilon=1$ if $(d-1)>0$ and $\varepsilon=-1$ in the case inverse. With Eq. (17), this solution allows to determine the velocity and film thickness. For $\left|\omega_{0}\right| \ll 1$, it can be developed in Taylor series. By using the mean velocity $u_{0}$ to express the approximate solution, it becomes:

$$
V=\frac{1}{2}\left(1+u_{0}+\frac{5}{12} u_{0}^{2}-\frac{1}{12} u_{0}^{3}+\ldots\right) \quad \text { and } \quad d=1-u_{0}+\frac{1}{12} u_{0}^{2}+\frac{5}{12} u_{0}^{3}+\ldots
$$

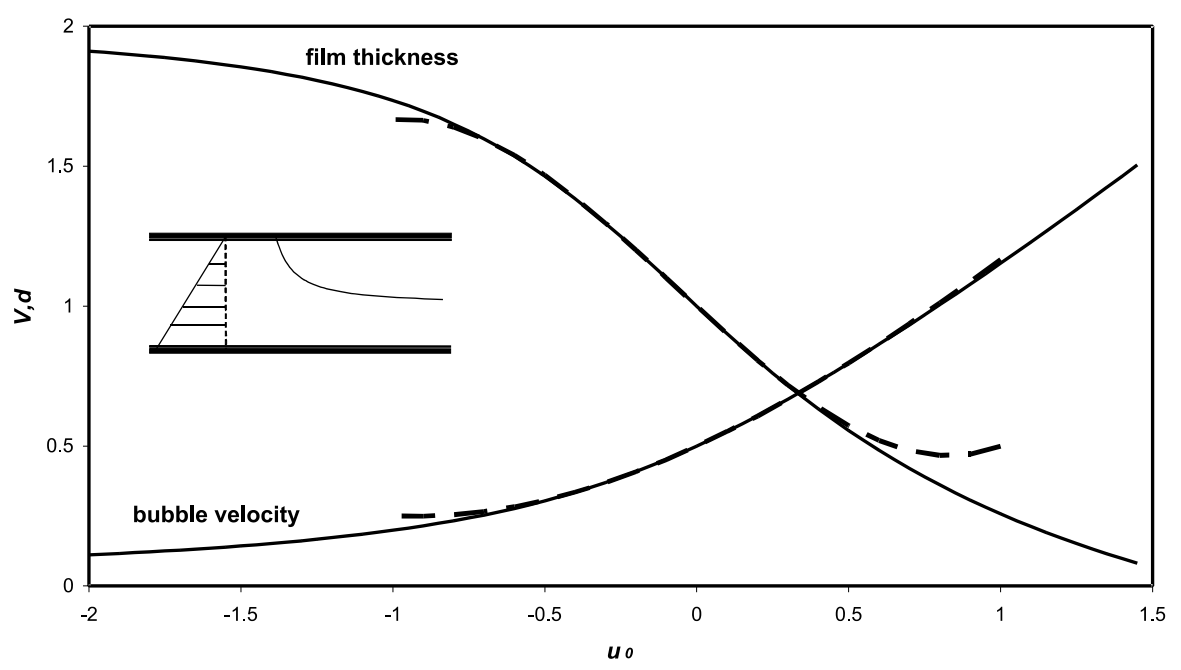

Fig. 2. Bubble velocity and film thickness in Couette flow: — exact solution, --- approximate solution

In Fig. 2 we presented the solutions for $u_{0}$ ranging between -2 and +1.5 . It can be observed that the approximate solution gives excellent results when $u_{0}$ ranging between -0.5 and +0.5 . When the lower wall is moved at the velocity $2 u_{0}$, it induces a mean liquid velocity $u_{0}$ in the channel. The additional velocity $\Delta V$ which results from it is thus in first order approximation equal to $u_{0} / 2$, i.e. half the mean velocity. The additional motion of the bubble is thus not due to the advection by the average flow, but it is above all very sensitive to the velocity distribution near the stagnation point. In the first order approximation, all occurs in fact as if the bubble were advected by the average flow in the upper half of the channel.

\subsection{Poiseuille flow upstream of the bubble}

Let us examine now the case where the bubble is pushed by a flow with variable vorticity. The bubble velocity and the film thickness are obtained by solving the equations (12) to (15). However, when the vorticity $\omega$ is a monotone function of $\psi$, it can be obtained an expression for $u(Y)=u(+\infty, Y)$ in explicit form. Indeed, in section $\mathrm{C}$ it can be written:

$$
d u^{2}=-\left(2 \omega \frac{d \psi}{d Y}\right) d Y
$$


By noting that $u^{2}(Y=1)=u_{C}^{2}=2-d$, and taking account (6), we can obtain:

$$
u^{2}(Y)=2-d-u_{a}(Y)\left(2 V-u_{a}(Y)\right) \text {. }
$$

By using the change of variables : $d y=-\frac{d u}{\omega}=-\frac{1}{\omega} \frac{d u}{d Y} d Y$, and taking account of $y(1)=d-1$, we can deduce that:

$$
\begin{gathered}
d=\int_{-1}^{1} \frac{V-u_{a}(Y)}{u(Y)} d Y, \\
\int_{-1}^{1}\left[V-u_{a}(Y)\right]^{2} d Y+\left(1-V^{2}\right)=\int_{-1}^{1}\left[V-u_{a}(Y)\right] u(Y) d Y+\frac{d^{2}}{4},
\end{gathered}
$$

The solution of the system of equations (19)-(20) allows to determine the two unknown $V$ and $d$ for a given velocity distribution $u_{a}(y)$.

For Poiseuille flow the velocity profile is parabolic and given by

$$
u_{a}(y)=\frac{3}{2} u_{0}\left(1-y^{2}\right)
$$

The system of equations (19)-(20) can be solved numerically by the Newton method to obtained an exact solution for $V$ and $d$. However, an approximate solution can be obtained in the form of Taylor series for $u_{0} \ll 1$ :

$$
V=\frac{1}{2}\left(1+u_{0}+\frac{1}{4} u_{0}^{2}-\frac{4}{35} u_{0}^{3}+\ldots\right), \quad d=1-u_{0}+\frac{1}{20} u_{0}^{2}+\frac{1}{7} u_{0}^{3}+\ldots
$$

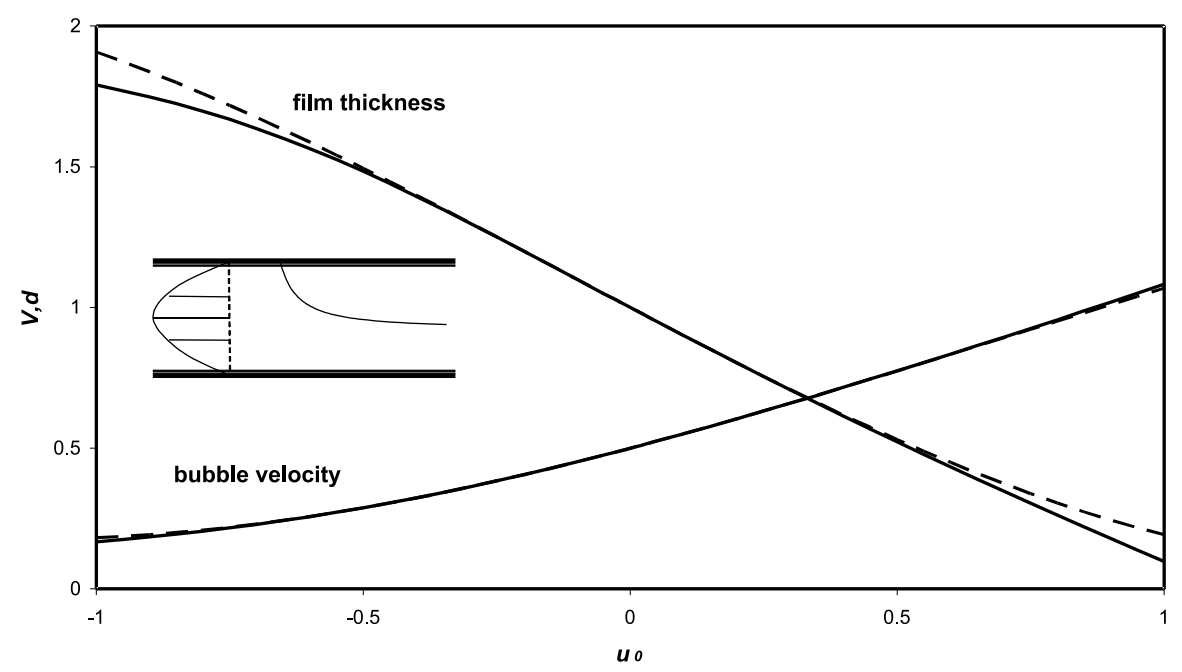

Fig. 3. Bubble velocity and film thickness in Poiseuille flow: - exact solution, --- approximate solution 
In Fig. 3 the variations of $V$ and $d$ with $u_{0}$ in the range $-1<u_{0}<1$ are presented. The approximate solution for velocity (21) agrees well with the numerical solution in all the range. With regard to the film thickness, the validity of the equation (21) is limited to $-0.5<u_{0}<0.5$. It's worth to note that in both flow cases, the approximate solutions for velocity and film thickness (Eqs (18) and (21)) are identical to first order. They differ only by the term in $u_{0}^{2}$.

\section{DISCUSSION}

In both cases, the approximate solution at the first order is identical. It is then independent of the velocity distribution upstream of the bubble. So by returning to the dimensional variables, we can write:

$$
V=0.5 u_{0}+0.5 \sqrt{g D}+O\left(u_{0}^{2} / \sqrt{g D}\right) .
$$

The solution of the first order shows also a surprising result: the bubble is advected, not by the average flow but by a velocity equal to half of the mean velocity.

By taking $V_{\infty}=0.5 \sqrt{g D}$ in (1), the $C_{0}$ coefficient, is given approximately by:

$$
C_{0}=0.5+V_{2}\left(u_{0} / \sqrt{g D}\right)+O\left(u_{0}^{2} / g D\right)
$$

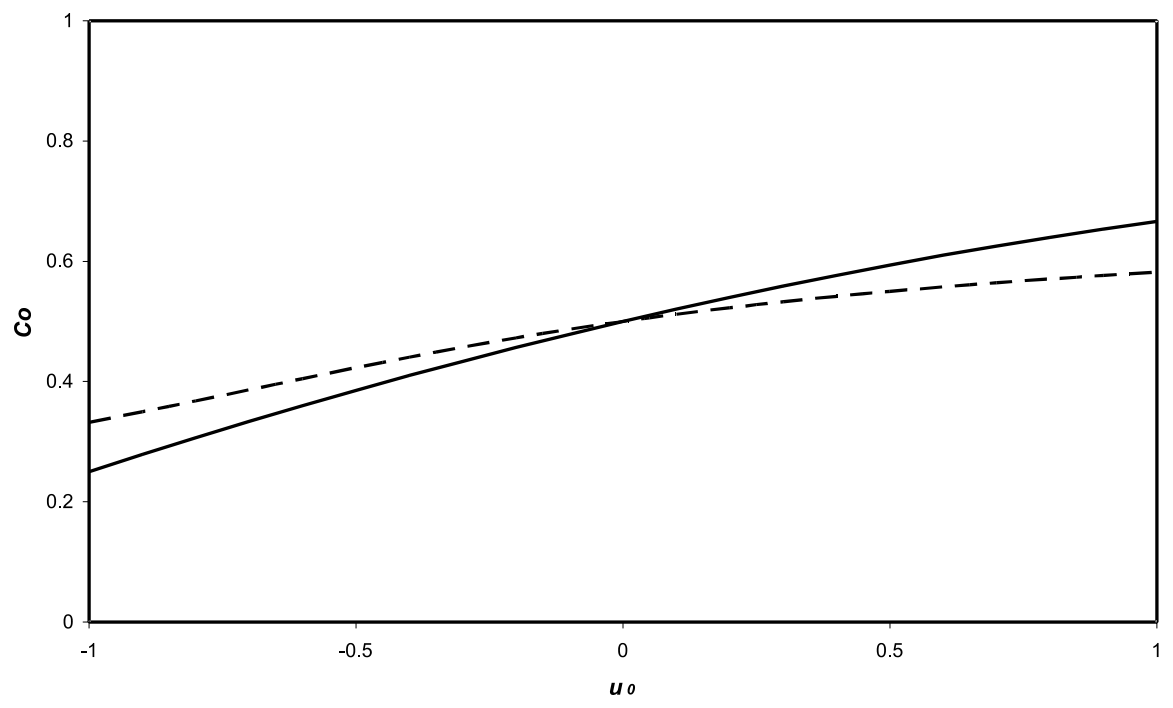

Fig. 4. Variation of coefficient $C_{0}$ : - Couette flow, - - - Poiseuille flow

Thus it is not constant and it varies with the Froude number $\left(u_{0} / \sqrt{g D}\right)$ of the average flow. It also depends on the velocity distribution upstream of the bubble by the coefficient $V_{2}$ as seen in Fig. 4. It can be noted that the less uniform the velocity distribution is the more sensitive the coefficient to the mean velocity. 
Ha Ngoc Hien, Jean Fabre

\section{REFERENCES}

[1] Nicklin, D. J., Wilkes, J. O. \& Davidson, J. F., Two-phase flow in vertical tubes, Trans. Inst. Chem. Eng. 40 (1962) 61-68.

[2] Collins, R., De Moraes, F. F., Davidson, J. F., \& Harrison, D., The motion of a large gas bubble rising though liquid flowing in a tube, J. Fluid Mech 89 (1978) 497-514.

[3] Bendiksen, K. H., On the motion of long bubbles in vertical tubes, Int. J. Multiphase Flow $11(1985)$ 797-812.

[4] Benjamin, T. B., Gravity currents and related phenomenon, J. Fluid Mech. 31 Part 2 (1968) 209-248.

[5] Lamb, H., Hydrodynamics, Cambridge University Press (1932).

[6] Batchelor, G. K., An Introduction to Fluid Dynamic, Cambridge University Press (1967).

Received April 14, 2010

\section{VẬN TỐC CỦA TÚI KHÍ TRONG CHẤT LỎNG CHUYỂN ĐộNG TRONG KÊNH NẰM NGANG}

Bài báo trình bày nghiên cứu lý thuyết về ảnh hưởng của dòng chảy chất lỏng lên chuyển động của túi khí trong kênh nằm ngang. Phương pháp Benjamin (1968) được mở rộng cho trường hợp chất lỏng chuyển động với giả thiết bỏ qua hiệu ứng nhớt và sức căng bề mặt, chuyển động của chất lỏng phía trước túi khí được mô tả bởi trường vận tốc cho trước. Lời giải chính xác cho vận tốc túi khí và chiều dày của lớp chất lỏng được biểu diễn dưới dạng tích phân. Lời giải giải tích gần đúng nhận được khi vận tốc trung bình của chất lỏng đủ nhỏ. Hai dạng trường vận tốc được nghiên cứu: dòng chảy Couette và dòng

chảy Poiseuille. Ở xấp xỉ bậc một, lời giải của hai trường hợp là như nhau. Ảnh hưởng của phân bố vận tốc chỉ xuất hiện ở xấp xỉ bậc cao hơn. 